\title{
¿CÓMO FORTALECER LA LABOR LEGISLATIVA DEL CONGRESO? \\ PROPUESTA PARA UN NUEVO SISTEMA DE ASESORÍA PARLAMENTARIA ${ }^{1}$
}

\section{Salvador Valdés Prieto y Sebastián Soto Velasco}

En este trabajo se proponen medidas para fortalecer la labor legislativa en Chile, con el fin de mejorar la calidad de las leyes y prestigiar la actividad política. Estas medidas persiguen, a la vez, evitar el desvío de recursos de asesoría legislativa hacia el trabajo distrital que realizan los parlamentarios, como también buscan evitar que los grupos de presión capturen la lealtad de asesores legislativos clave. Se propone crear un sistema nuevo de asesoría interna radicado en cada uno de los comités (bancadas), con un total de noventa nuevos asesores.

Palabras clave: Congreso, legislación, comités parlamentarios, grupos de presión, burocracia.

Salvador ValdÉs. Doctor en Economía, MIT. Profesor Titular de Economía, P. Universidad Católica de Chile e investigador del Centro de Estudios Públicos.

Sebastián Soto. Master en Derecho, Universidad de Columbia. Profesor de la Facultad de Derecho, P. Universidad Católica de Chile, y director del Programa de Asesoría Legislativa del Instituto Libertad y Desarrollo. Participó como becario Fulbright en el Congressional Fellowship Program en los Estados Unidos, desempeñándose como staffer en la oficina del senador federal Norman Coleman (Minnesota).

${ }^{1}$ Se agradece la información obtenida en conversaciones con Isabel Millán, Soledad Ferreiro, Hernán Ampuero, Manuel José Guzmán, Rubén Catalán y el senador Sergio Romero, así como el acceso al informe de Rafael Blanco, Axel Buchheister, Eolo Díaz-Tendero y Marcelo Venegas (2006), encargado por BCN-Innova. También se agradecen los comentarios recibidos de Ena von Baer, Harald Beyer, Axel Buchheister, Cristián Larroulet, Carmen le Foulon y Carolina Segovia, y finalmente los formulados por Rodrigo Álvarez, presidente de la Cámara de Diputados, y por Alfredo Joignant en seminario realizado recientemente en el CEP.

Estudios Públicos, 114 (otoño 2009). 
$A_{\text {lgunos estudios han calificado al Congreso chileno como }}$ uno de los más constructivos de la región (BID, 2005), aunque también hay opiniones en contrario. Con todo, hay problemas que afectan el ejercicio de la función legislativa y que inciden, finalmente, en la idoneidad de las leyes promulgadas. Este trabajo propone soluciones para fortalecer la labor legislativa de los parlamentarios y mejorar, en beneficio de la ciudadanía, la calidad de las leyes de nuestro país.

En la actualidad, el Poder Ejecutivo concentra la mayor red de asesores para la elaboración de los proyectos de ley, lo cual, junto a otras herramientas institucionales que están a su disposición, le otorga una capacidad de acción difícil de ser contrarrestada por los parlamentarios (Godoy, 2003; Siavelis, 2001). Ello redunda en que el aporte técnico del Congreso Nacional en la discusión legislativa sea exiguo, pues los parlamentarios tienen escasas posibilidades de contrastar cifras, datos, interpretaciones legales o experiencias comparadas que sirvan de base a los argumentos del Poder Ejecutivo. Otras razones institucionales también contribuyen a que la labor del Congreso sea más bien reactiva a las propuestas del Ejecutivo (BID, 2005), lo cual dificulta un trabajo legislativo más creativo e impone obstáculos a los parlamentarios que quisieran lucirse como legisladores.

Si se analiza la percepción de la opinión pública, lo anterior se traduce en una imagen en que el Congreso aparece más bien dificultando la aprobación de las leyes y no como una entidad que las perfecciona tras una deliberación democrática. Así, por ejemplo, la comparación que hace Latinobarómetro entre los congresos de la región indica que ha ido disminuyendo la posición relativa de Chile en los últimos años, ubicándose hacia 2008 en el lugar número 14, dentro de un total de dieciocho congresos latinoamericanos, en cuanto al porcentaje de los encuestados que consideran que el trabajo del parlamento es bueno o muy bueno. El Congreso chileno es superado por todos excepto por los de Bolivia, Guatemala, Panamá y Perú (Latinobarómetro, 2008, p. 85). Este índice corrobora a su vez los resultados de una encuesta realizada entre marzo y abril del 2008, según los cuales el 59\% de los encuestados estima que los partidos políticos dificultan la aprobación de leyes, mientras que sólo el $29 \%$ considera que los partidos facilitan/ayudan a aprobar las leyes en el parlamento ${ }^{2}$. Sin embargo, esta percepción

${ }^{2}$ Consorcio de Centros de Estudio, "Estudio Nacional sobre Partidos Políticos y Sistema Electoral”, marzo-abril 2008. 
puede obedecer a otros factores, como los conflictos entre partidos y entre parlamentarios.

La disyuntiva entre un Poder Ejecutivo con poderes casi monopólicos en materias legislativas y un Congreso con reducidas capacidades ha intentado ser salvada por diversas vías ${ }^{3}$. Una de éstas ha sido fortalecer la capacidad técnica del Congreso creando sistemas de asesoría legislativa que sirvan de contrapeso al rol del Ejecutivo, los cuales han sido instaurados poco a poco desde la década de los 90. Sin embargo, según la opinión de expertos, estos esfuerzos no han logrado crear asesorías legislativas eficaces hasta el momento (Blanco, Buchheister, Díaz-Tendero y Venegas, 2006).

Este trabajo ofrece un análisis de las asesorías legislativas actuales y propone soluciones específicas para aumentar las capacidades técnicas del Poder Legislativo y permitir, al mismo tiempo, que éste opere como un efectivo contrapeso al Ejecutivo. Para ello se recurre a la literatura internacional y a la evidencia y experiencia chilenas.

Entre las medidas que se plantean, la más novedosa consiste en superar las tradicionales combinaciones entre asesoría legislativa personal y asesoría "neutral", para crear un tercer tipo de asesoría, que es política sin ser personal. Se trata de una asesoría controlada colectivamente por cada "bancada" o comité parlamentario. Este diseño, desarrollado a partir de una de las propuestas de Valdés (2008), brinda asesoría política y por tanto de confianza, pero al ser colectiva baja el riesgo de captura por las demandas del trabajo distrital y favorece la profesionalización.

La sección 1 define los objetivos de un buen sistema de asesoría legislativa. La sección 2 describe en detalle la situación actual, revelando la multiplicidad de fuentes de asesoría que operan en la práctica. Esta sección también cuantifica los recursos disponibles según la información que pudimos reunir. La sección 3 presenta los sistemas posibles y vigentes para exigir un desempeño de calidad a los asesores legislativos. La sección 4 contiene nuestra propuesta: crear un sistema nuevo de asesoría interna, radicado en los Comités (bancadas), y ampliar la externa financiada por el Congreso. La nueva asesoría interna financiaría 90 asesores, sumando ambas cámaras. El costo fiscal de ambas propuestas se estima en 8,9 millones de dólares al año. Al final del trabajo se incluye un Anexo que ofrece un resumen de la experiencia del Congreso de los EE.UU. en materia de asesoría legislativa.

\footnotetext{
${ }^{3}$ Estas iniciativas van desde modificar el régimen de gobierno, reformar el sistema de urgencias, modificar las materias de iniciativa exclusiva del Presidente de la República, entre otras.
} 


\section{OBJETIVOS Y RIESGOS}

Los objetivos generales del gasto público en asesoría legislativa son (Meller, 1967):

a) Vincular el trabajo político de representación al conocimiento de los expertos. Con esta vinculación se espera contribuir a que la legislación eleve su efectividad en sociedades complejas, como la moderna;

b) Reducir la asimetría de información que existe a favor del Poder Ejecutivo, en perjuicio de los parlamentarios;

c) Reducir la asimetría de información que existe a favor de los grupos de presión, en desmedro de los parlamentarios. En efecto, los parlamentarios suelen recibir de los grupos de presión información favorable a los intereses de los propios grupos, sea en forma directa, a través de intermediarios (lobbyists), o de maneras aún más indirectas.

En el caso actual de Chile existe un objetivo adicional que consiste en elevar la calidad de la política, permitiendo a los parlamentarios y a sus partidos desarrollar una faceta que hasta ahora ha sido débil: la de ser puente entre el conocimiento de los expertos y las necesidades de la ciudadanía que los partidos identifican a través de sus distintas actividades extraparlamentarias.

El logro de estos objetivos no está libre de riesgos, debido a que abundan las consecuencias no previstas de aumentar el gasto en asesoría legislativa.

La evidencia empírica de Japón entre 1948 y 1956 y del Estado de Hawaii entre 1937 y 1955 muestra que la ampliación del personal general del Congreso encargado de redactar leyes en forma objetiva y sin vínculos personales con los legisladores provocó un fuerte aumento en el número de leyes aprobadas por año, porque “el aumento de personal alentó a los parlamentarios a pedir más proyectos” (Meller, 1967). No sabemos si ello redundó en más legislación necesaria y de mayor calidad o en una masa mayor de regulaciones innecesarias que en conjunto frenan el desarrollo económico y social. Por otra parte, algunos autores achacan a los demasiado poderosos asesores legislativos la 
responsabilidad de introducir un exceso de detalles regulatorios en las leyes (Mann y Ornstein, 1992, p. 67, citado por Romzek y Utter, 1996). Y, en fin, también existe el riesgo de generar una nueva clase de burócratas capaces de imponer ritmos, prácticas y comportamientos que reducirían la capacidad de los parlamentarios para legitimarse ante su electorado representando fielmente sus intereses de largo plazo (Dodd 1993, citado por Romzek y Utter, 1997). En otras palabras, un cuerpo de asesores demasiado profesionalizado podría capturar el proceso legislativo para sí mismo, en perjuicio de la influencia ciudadana.

Un punto a considerar, aunque no es sencillo de interpretar, es que en los Estados Unidos el Congreso federal contaba hacia fines del siglo XIX con 140 asesores, cifra que cien años después se elevaba a 23.000 staffers (Davidson y Oleszek, 2004, p. 28).

Otra consecuencia no prevista de una asesoría legislativa mal diseñada sería facilitarles la tarea a los grupos de presión que desean influir sobre la legislación por la vía de capturar la lealtad de asesores legislativos clave. Como veremos, este riesgo puede evitarse si el diseño institucional es adecuado.

Todos estos factores deben ponderarse al momento de elaborar una propuesta. Creemos que el relativo consenso que existe en Chile en torno a la escasa capacidad legislativa del Congreso debiera permitir avanzar hacia la creación de un sistema de asesoría legislativa que sirva como herramienta efectiva para mejorar el debate de política pública en el Congreso chileno, siempre que se identifique un diseño institucional adecuado.

\section{FUENTES DE ASESORÍA PARA LEGISLAR: LA SITUACIÓN DE PARTIDA}

Una forma útil de clasificar la asesoría que recibe un parlamentario es en razón de la identidad de quien presta o filtra dicha asesoría. Cada una de estas fuentes de información es operada por "asesores legislativos" de hecho, sean formales o no. A continuación daremos una mirada a las diversas fuentes de asesoría legislativa presentes hoy en Chile ${ }^{4}$. La distinción más amplia es entre aquella asesoría prestada por asesores no dependientes del Congreso y la prestada por asesores dependientes del o financiados desde el Congreso.

\footnotetext{
${ }^{4}$ Para una revisión de la asesoría legislativa en el período 1960-1989 en Chile, ver Oelckers (1993).
} 


\subsection{Asesoría legislativa financiada por el Congreso}

\section{1.a) Asesoría personal}

Esta asesoría legislativa se define como aquella prestada por asesores designados personalmente por el propio parlamentario. Al designarlos y despedirlos, éste se asegura de que sus asesores tomen en cuenta sus principios y posiciones políticas; lo mantengan informado del debate legislativo y le ayuden a tomar parte activa en él; lo protejan y mejoren su imagen pública; lo ayuden a manejar la información dada por fuentes externas; y lo ayuden a lidiar con los grupos de presión. Este asesor cuenta con la confianza política de su parlamentario, lo que facilita el contacto entre ambos y hace más efectiva la asesoría prestada.

Este tipo de asesores legislativos es el que predomina, en términos numéricos, en el Congreso de los EE.UU. (sobre el personal de apoyo legislativo en el Congreso de los EE.UU., véase Anexo). El atributo que distingue a este asesor legislativo de los demás es la lealtad personal al parlamentario.

En Chile, tanto senadores como diputados tienen recursos asignados para la contratación de personal que, en la medida que el congresista lo determine, puede incluir asesores legislativos ${ }^{5}$. Sin embargo, como veremos, el mecanismo de contratación directa por parte del legislador no garantiza que los recursos sean invertidos efectivamente en potenciar la calidad del trabajo legislativo. Más bien el incentivo está dado a dirigir esos recursos a fortalecer el trabajo en terreno y las opciones de reelección.

\section{1.b) Asesoría neutral}

Es la asesoría legislativa que prestan diversas instancias al interior del Congreso. Los asesores, en este caso, están obligados a servir a todos los parlamentarios en forma equitativa y sin diferencias arbitrarias (Ampuero, 2006). Este tipo de asesoría promueve un debate más informado transversalmente y facilita el diálogo entre partidos rivales. Ello no sólo perfecciona el contenido de las políticas públicas, sino que también

${ }^{5}$ Cada diputado tiene asignado para remuneración de secretarios y asesores algo menos de \$ 3 millones. Las cifras informadas por los senadores varían en cada caso. 
eleva la legitimidad de las mismas (Robinson, 2002). En Chile, la asesoría neutral opera en diversas instancias.

2.1.b.i) La Biblioteca del Congreso Nacional (BCN) ha aumentado la oferta de este tipo de asesoría desde fines de 2006, continuando el proyecto "BCN-Innova" que incorporó algunos resultados obtenidos por el proyecto que desarrolló el senador S. Romero (RN) entre 2005 y abril de 2006. Este proyecto ha sido financiado a la fecha por medio de un aporte del Banco Interamericano de Desarrollo. A marzo de 2009, la BCN cuenta con 59 profesionales dedicados a la asesoría parlamentaria neutral ${ }^{6}$.

Para efectos de asesoramiento al trabajo legislativo, la labor de la BCN se organiza en áreas temáticas (legal, económica, recursos naturales, políticas sociales, etc.), emitiendo informes especializados. Además, estos asesores prestan servicios de apoyo a las funciones parlamentarias de representación?.

La información disponible no permite determinar si la aproximación de estos asesores a las discusiones legislativas es efectivamente neutral, o si tienden a tomar partido por algunas de las posturas en debate. Tampoco es posible determinar si el apoyo a las funciones parlamentarias de representación se traduce en ventajas significativas para la reelección de los parlamentarios en ejercicio en perjuicio de otros candidatos desafiantes, que aún no son parlamentarios y no acceden a estos apoyos ${ }^{8}$. A la fecha, este tipo de asesoría carece de principios claros para definir el modo como abordarán la asesoría parlamentaria.

2.1.b.ii) En el Senado, la Oficina de Informaciones es la institución que, además de la tramitación de oficios al Poder Ejecutivo, tiene asignada como una de sus tantas tareas la de prestar asesoría legislativa

${ }^{6}$ Entrevista con Isabel Millán, Jefa del Departamento de Servicios Legislativos y Documentales, BCN. Las áreas temáticas son cinco: legal, económica, recursos naturales, social y relaciones exteriores y defensa.

${ }^{7}$ Véase BCN: Manual de Asesoría Parlamentaria, 2009.

${ }^{8}$ Algunos de los servicios que ofrece la BCN a los legisladores tienden a favorecer la reelección de los candidatos titulares, en perjuicio de los desafiantes. El caso más claro es el denominado "texto guiado", que es un documento que contiene discursos o conferencias que dictará el parlamentario. En este caso la BCN asume una postura parcial, la del legislador, para proporcionarle sustento al parlamentario en sus labores de representación, las que también sirven de precampaña para su reelección. 
a los senadores o comisiones legislativas que lo requieran. Las 13 personas que trabajan en dicha oficina elaboran diversos informes y dan respuesta a todo tipo de consultas que, en forma verbal o escrita, hacen llegar los senadores. Según estadísticas elaboradas por esta misma oficina, durante el año 2008 se dieron respuesta a 141 consultas de los senadores. Considerando un total de 38 senadores y 11 meses de actividad al año, este servicio respondió un promedio de 0,3 consultas por senador al mes. Esta cifra confirma que la asesoría legislativa no es la labor más importante de la Oficina de Informaciones del Senado, sino que la tramitación de oficios que, durante el 2008, alcanzaron a 1.284 oficios de consulta.

2.1.b.iii) En la Cámara de Diputados, la Oficina de Informaciones cumple funciones similares a las de su par en el Senado. Las 24 personas que trabajan en ella, además de la tramitación de los oficios al Poder Ejecutivo, también tienen entre sus funciones la elaboración de informes jurídicos y la resolución de las consultas de los diputados. Desafortunadamente esta oficina no lleva información respecto al número de gestiones que realiza, por lo que se hace más complejo evaluar su trabajo.

Por otra parte, la Cámara de Diputados cuenta también desde 1997 con un sistema de asesoría externa, que permite a aquellas instituciones asesoras inscritas en un registro elaborar informes para apoyar su función legislativa. Estos informes son luego financiados con cargo a fondos del Congreso Nacional. Una Comisión Especial de Asesoría Externa elabora anualmente el registro de entidades asesoras y la Oficina de Informaciones administra el sistema.

A modo de ejemplo puede señalarse que el año 2008 el monto asignado a los diputados, a la mesa de la Cámara de Diputados y a los comités por concepto de asesoría externa fue de \$ 329 millones — de los cuales el gasto ejecutado alcanzó el 95\%-. En el mismo período se firmaron 116 contratos por concepto de asesoría legislativa externa con 25 instituciones que van desde una universidad (la Universidad de Talca), hasta centros de estudios (el Centro de Estudios para el Desarrollo, la Fundación Jaime Guzmán y el Instituto Libertad), y una serie de personas jurídicas. Es dudoso que toda esta asesoría sea neutra, aunque aquella prestada por universidades podría serlo. Por esto, la asesoría externa es mencionada nuevamente al cubrir la asesoría calificada políticamente. 
2.1.b.iv) Comisión Especial Mixta de Presupuestos. El año 2003 el Congreso Nacional concedió carácter permanente a la Comisión Especial Mixta de Presupuesto (CEMP) que, hasta esa fecha, se reunía sólo entre los meses de octubre y diciembre para estudiar el presupuesto anual de la Nación ${ }^{9}$. La ley que le dio carácter permanente también dispuso que la CEMP pudiera solicitar, recibir, sistematizar y examinar la información relativa a la ejecución presupuestaria proporcionada por el Ejecutivo. Para ello dispuso que la CEMP contará con una unidad de asesoría presupuestaria. Poco después de aprobada dicha ley, se formó en el Congreso Nacional una comisión de senadores y diputados que propondría las bases para la formación de esta unidad. Sin embargo, esta comisión no llegó a acuerdo para formar una estructura bicameral. No hay claridad respecto a las razones que impidieron crear una unidad de asesoría presupuestaria que aunara los esfuerzos de ambas cámaras para estudiar la ejecución del presupuesto.

De este modo, por una parte el Senado cuenta con una Oficina de Presupuesto compuesta por tres personas que dependen de la Comisión de Presupuestos y, por la otra, la Cámara de Diputados incorporó a algunos funcionarios a la Oficina de Informaciones para efectos de colaborar con el trabajo de esta misma Comisión.

2.1.b.v) Secretarios de comisión. Cada comisión, sea ésta permanente, especial o investigadora, cuenta con dos abogados que actúan como ministros de fe y prestan asesoría en materias netamente legislativas. Otros funcionarios de ambas cámaras, sin ser partes de comisiones, también juegan un rol asesorando en temas jurídico-legislativos a los respectivos presidentes de ambas corporaciones. A diferencia de lo que ocurre en Estados Unidos, en nuestro país estas personas son funcionarios de planta del Congreso y no dependen para su designación de la confianza que ponga en ellos el presidente de la comisión temática donde trabajan.

\section{1.c) Asesoría "precalificada por los partidos políticos”}

2.1.c.i) Esta asesoría está financiada en primer lugar por los comités. Ellos son los organismos que agrupan a diputados o senadores de un mismo partido político de una misma cámara del Congreso,

${ }^{9}$ Según lo establecido en la Ley No 19.875, D. O. 28 de mayo de 2003. 
llamados también "bancadas". A través de su jefe, los comités canalizan la relación entre la mesa de la corporación respectiva y sus miembros. Los legisladores independientes tienen reglas especiales para formar parte de un comité o crear uno propio.

Los comités cuentan con recursos especiales que destinan a contratar personal para la asesoría legislativa ${ }^{10}$. Por ser partidista, esta asesoría legislativa está nutrida del contacto con la ciudadanía que desarrolla cada partido parlamentario en sus demás actividades en los distritos, y también por el contacto logrado por aquella parte del mismo partido que opera fuera del Congreso. El hecho de que estos asesores legislativos deban contar con la confianza política de los miembros del comité partidista, y quizá también con la confianza de la directiva del partido fuera del Congreso, permite que el trabajo asesor-legislador sea más coordinado.

2.1.c.ii) En segundo lugar, debe incluirse aquí aquella parte de la asesoría externa asignada por los diputados, la mesa de la Cámara de Diputados y los comités, que es prestada por centros de estudios y otras personas jurídicas que tengan una cercanía clara con un partido o grupo de partidos. Recordemos que otra parte de estos gastos fue clasificada como asesoría política neutral.

\subsection{Asesores legislativos no dependientes del Congreso}

Buena parte de la asesoría de este tipo es "precalificada políticamente”, a excepción del lobby.

\section{2.a) Partido político o think-tank afiliado a un partido político}

Los partidos políticos pueden ser organizaciones mucho más amplias que un grupo de parlamentarios y sus asesores. En especial los partidos más grandes tienen militantes, donantes, actividades regulares, directivas destacadas e influyentes, y empleados permanentes. Entre estos últimos puede haber asesores legislativos, destinados a apoyar a los parlamentarios del partido. A diferencia de los asesores considera-

${ }^{10}$ Cada comité en la Cámara de Diputados recibe mensualmente \$ 2.193.356 y para conformar uno se requieren nueve diputados. En el Senado, cada senador recibe \$ 2.463.071 mensuales para destinarlos a los comités. 
dos anteriormente, éstos son leales a la directiva del partido, que puede estar integrada y controlada por líderes que no son parlamentarios.

También existen centros de estudios afiliados a partidos políticos que, en ocasiones, reciben asignaciones para asesoría legislativa que reparte la Cámara de Diputados a través del sistema de asesoría externa (véase supra, 2.1.c.ii).

\section{2.b) Think-Tank no afiliado a un partido específico}

La asesoría "precalificada por un think-tank" también provee información de gran utilidad a un parlamentario. Esta asesoría puede ser neutral en el sentido partidista estricto, pero expresa la orientación general que define al think-tank. Habitualmente esa orientación implica una cercanía mayor con ciertos partidos.

\section{2.c) Poder Ejecutivo}

La asesoría "precalificada por los intereses del poder ejecutivo" se otorga en forma privilegiada a los parlamentarios oficialistas, pero es controlada por el Poder Ejecutivo, no por los partidos oficialistas ${ }^{11}$. La asesoría consiste en que el Poder Ejecutivo destina a parte de su staff de exclusiva confianza a prestar servicios privados de asesoría a ciertos parlamentarios oficialistas. Las asesorías del Poder Ejecutivo a parlamentarios oficialistas pueden generar una asimetría al interior de la coalición y también en desmedro de la oposición, pues esta última no accede al presupuesto público en la misma escala que el Poder Ejecutivo. Esta asimetría reduce la competencia política y puede perjudicar a la ciudadanía. En Chile no existen cifras públicas sobre los recursos destinados a esta labor.

\section{2.d) Lobby}

La asesoría "precalificada por un lobbyist" también provee información útil al parlamentario y a sus asesores. Cuando estos últimos

${ }^{11}$ Cuando tratan un proyecto de ley que promueve el Poder Ejecutivo, todos los parlamentarios reciben las opiniones del Ejecutivo, pero es infrecuente que los parlamentarios de oposición reciban asesoría. 
desean actuar con independencia del lobbyist proveedor, y aprovechar al mismo tiempo la información que les proporciona el lobbyist para mejorar la legislación, deben realizar la tarea de cruzar la información recibida con otras fuentes con el fin de detectar sesgos y omisiones. Por el contrario, si el parlamentario desea intercambiar favores políticos con el lobbyist (corrupción política), no le será tan importante evaluar la información recibida.

Algunos lobbies también pueden intentar actuar en forma indirecta, financiando primero a un think-tank o a un partido político fuera del Congreso. Desde luego, el receptor de esas donaciones podría insistir en mantener su independencia del lobby, pues de lo contrario se arriesga a perder influencia en caso de que otros actores del proceso político estimen que ha sido capturado por dicho lobby. También puede ocurrir que un partido, o un político o un think-tank se sienta suficientemente protegido de la competencia como para optar por la independencia, al menos en algunos temas. No se conoce el volumen de recursos destinados a hacer lobby mediante la entrega de asesoría en forma directa a los parlamentarios, y menos aún de la que se entrega en forma indirecta.

\section{RENDICIÓN DE CUENTAS POR ASESORES LEGISLATIVOS DEL CONGRESO}

Es posible afianzar la calidad del trabajo de los asesores legislativos mediante prácticas de rendición de cuentas exigentes y coherentes en el tiempo (Romzek, 2000). Sin embargo, hay diversas dificultades:

- $\quad$ Debido a que el contexto en que deben operar los asesores legislativos es muy dinámico y variable, las tareas que deben efectuar tienden a estar definidas de manera general e imprecisa, dificultando que ellas puedan ser evaluadas en forma objetiva.

- $\quad$ Se requeriría una investigación exhaustiva de cada evento para distinguir entre un servicio del asesor que eleva la calidad de la legislación y un servicio del asesor a un grupo de presión que "regala" información. Hacer esa distinción puede exceder la habilidad de quien debiera exigir cuentas. 
- Los parlamentarios, tanto individual como colectivamente, tienen poco tiempo para evaluar el desempeño de sus asesores legislativos en forma continua.

En suma, la naturaleza de la tarea del asesor legislativo ofrece una amplia esfera para su discreción y criterio (Romzek y Utter, 1997, p. 1254). Esto impide aplicar los mecanismos tradicionales de rendición de cuentas, propios de las burocracias públicas y privadas. No obstante lo anterior, es posible diseñar distintas modalidades para diferentes tipos de asesoría.

Si bien todas las modalidades de asesoría legislativa presentan ventajas y debilidades en la rendición de cuentas, ellas difieren mucho entre sí según sea la identidad del empleador del asesor legislativo. La relación que sigue se propone entregar elementos que permitan identificar el mejor modelo para un sistema de asesoría legislativa.

\subsection{Asesoría legislativa personal}

En el caso de la asesoría legislativa personal, quien debería exigir cuentas al asesor es el propio parlamentario a quien sirve. Una ventaja de este sistema es que la cadena de delegación es corta y los incentivos son nítidos: la carrera política del parlamentario depende en parte de obtener el máximo esfuerzo de sus asesores legislativos.

Sin embargo, la asesoría personal también presenta sus propias dificultades. El parlamentario tiene otros intereses, adicionales al de exigir cuentas a sus asesores legislativos, que pueden sesgar el ejercicio de su función de controlar y vigilar al asesor personal. Un parlamentario se interesa en tres clases de ayuda:

- Asesoría que contribuye al desempeño y accionar exitoso de cada parlamentario en el ámbito de la representación. En este caso la labor del asesor se orienta al trabajo distrital para ganar la reelección, o para designar un sucesor en el distrito.

- $\quad$ Asesoría en el ámbito de la fiscalización parlamentaria al Poder Ejecutivo $^{12}$.

- Asesoría en el ámbito de las tareas legislativas propiamente tales.

12 En Chile, sólo en el caso de los diputados. Los senadores no tienen poder fiscalizador explícito, aun cuando lo ejercen en la práctica. 
En teoría, sería posible ganar la competencia electoral haciendo mejores leyes. Sin embargo, la evidencia muestra que el voto es más sensible a la calidad y cantidad del trabajo distrital que a la calidad de la legislación que logró el candidato en su condición de parlamentario. En efecto, una encuesta encargada por la Biblioteca del Congreso Nacional y publicada el año 2006 muestra que el 61\% de los encuestados prefiere que los congresistas destinen parte importante de su tiempo a escuchar y resolver los problemas de la gente en su zona aunque esto signifique menos tiempo para su trabajo legislativo. Solo el 36\% prefiere que los legisladores se dediquen a hacer un buen trabajo legislativo (Datavoz, 2006). Este comportamiento de los votantes no es caprichoso, sino que obedece al alto costo que tiene procesar información sobre cómo determinadas leyes afectan la realidad en nuestra compleja sociedad (Caplan, 2007).

Así, cuando un parlamentario recibe recursos públicos para asesoría legislativa personal, y queda en libertad de destinarlos a cualquiera de estas tres funciones, casi siempre prioriza la representación e invierte el dinero en el distrito.

Esta situación se da en Chile desde 1990 con la asignación parlamentaria. Ésta es una suma mensual de recursos públicos que el parlamentario puede destinar a cualquiera de los tres usos mencionados. En la práctica, la gran mayoría de los parlamentarios utiliza casi la totalidad de ese monto en financiar oficinas distritales y sueldos del personal de apoyo que trabaja para su reelección. Esta excesiva prioridad que reciben las oficinas distritales sugeriría que existe subproducción del bien público "calidad legislativa” cuando las asignaciones parlamentarias pueden destinarse indistintamente a cualquiera de las tres funciones mencionadas.

Existe evidencia que respalda esa hipótesis. Revisamos el personal contratado por cada diputado según informa la página web de la Cámara de Diputados ${ }^{13}$. Los 115 diputados que entregan la información contratan en promedio a 7,6 personas cada uno, arrojando un total de 874 personas contratadas. Sólo 48 diputados informan las labores que ejerce cada una de las personas contratadas (los restantes sólo dan a

${ }^{13}$ Todos estos datos fueron tomados de www.camara.cl con la información que se encontraba disponible la semana del 23 de marzo de 2009. Con la entrada en vigencia de la ley de acceso a la información pública, la Cámara de Diputados ha modificado la información y ahora no es posible conocer el detalle de las funciones que desempeña cada una de las personas contratadas. 
conocer los nombres). De los contratados informados, sólo cuatro diputados tienen dos asesores legislativos o jurídicos, 21 diputados tienen sólo uno y el resto de los que informa, es decir 23 diputados, no contrata personas para la asesoría legislativa (www.camara.cl). Luego, el total de asesores informados es 29 , lo que entrega un promedio de 0,24 asesores legislativos por diputado. Del total de contratados, sólo el $1,0 \%$ es asesor legislativo. Esta evidencia avala la hipótesis de que son muy pocos los contratados para la función de asesoría legislativa.

Del 99\% restante, en general se contrata personal administrativo para mantener en funcionamiento las oficinas distritales, además de periodistas y asesores de imagen. De los casos informados, algunos son extremos:

- Diputado Escobar: un "terapeuta en reiki” para programa de atención distrital;

- Diputado Farías: un “nochero”, y

- Diputado Vallespin: un "encargado de fomentar la ley de culto”.

No contamos con datos comparables respecto de los senadores ${ }^{14}$.

En suma, la asesoría legislativa personal puede aumentar los fondos públicos en favor de la campaña de reelección de los parlamentarios titulares en forma asimétrica porque no se entregan fondos comparables a los candidatos desafiantes. Esta asimetría, por tanto, puede reducir la competencia política, en perjuicio de la ciudadanía.

Podría idearse un mecanismo para disminuir este riesgo si, por ejemplo, la ley exigiera que el asesor legislativo trabaje exclusivamente en el Congreso y no pudiera visitar el distrito o zona del parlamentario para el que trabaja. Sin embargo, este tipo de fórmula no sólo es muy difícil de fiscalizar sino que también introduce un mecanismo excesivamente rígido que probablemente amenazaría la efectividad del asesor. Además, todavía subsistirían formas sutiles de desviación. Por ejemplo, el parlamentario igualmente podría encargar la gestión del trabajo en terreno al asesor pero encargándole que la haga desde la sede del Congreso.

${ }^{14}$ En el caso de los senadores, la información disponible separa los gastos en asesoría legislativa de aquellos que corresponden más propiamente a la labor parlamentaria (oficinas, personal, etc.). Los primeros incluyen tanto a asesoría legislativa personal como asesoría externa. 
Respecto a los lobbies, la asesoría personal da pocas garantías a la ciudadanía. Por ejemplo, un parlamentario podría ceder el control sobre un asesor para congraciarse con determinado grupo de presión o lobby. Existe también el caso contrario, en que el parlamentario designa a ciertos asesores con el fin de aparentar la entrega de poder a un asesor cuyo perfil es bien recibido por el grupo de presión, sin entregar dicho poder en la realidad ${ }^{15}$.

\subsection{Asesoría neutral}

La asesoría legislativa "neutral”, otorgada por cuerpos permanentes del Congreso, presenta ventajas y problemas de naturaleza diferente. Entre las ventajas destaca que el horizonte de largo plazo de estos empleos permite lograr altos grados de especialización y conocimiento. Por ejemplo, un asesor neutral especialista en políticas de salud podría conocer a sus pares en otros países y podría incorporar en sus asesorías a la Comisión de Salud las lecciones de la experiencia comparada. Otra ventaja es que este ambiente fomenta un ethos profesional, que podría incluir algunos de los estándares de calidad exigidos a sus pares de otros congresos o de instituciones académicas.

Sin embargo, la rendición de cuentas de los asesores neutrales presenta problemas. Primero, si estos asesores son realmente neutrales, los parlamentarios tenderán a desconfiar de ellos en términos políticos, y por tanto no les comunicarán sus estrategias. Por ello, en caso de verdadera neutralidad estas asesorías tienden a estar desconectadas de los parlamentarios y a ser menos eficaces.

Segundo, pocos parlamentarios están dispuestos a asumir los costos que, para su imagen pública, podría significar el mostrarse exigente con asesores que se declaran neutrales. El hecho de que éstos pueden presentarse como víctimas de una relación laboral abusiva, accediendo así a la empatía de buena parte de los electores, los deja libres de las presiones propias de una rendición de cuentas real, es decir, se pierde accountability.

${ }^{15}$ Respecto al Congreso de los Estados Unidos hay evidencia de que algunos congresistas ceden ante la insistencia de un grupo de presión y designan a un asesor legislativo a cargo del tema que tenga un perfil que le dé confianza a dicho grupo (Simon y Cohen, 2003). 
Tercero, los asesores neutrales pueden operar como un sindicato, que podría amenazar con dañar comunicacionalmente a aquellos parlamentarios que no cedan a sus demandas. Por eso, los asesores neutrales tienden a obtener condiciones de trabajo superiores a las que rigen en los mercados laborales comparables, a costa de los recursos de la ciudadanía. La captura del presupuesto del Congreso por parte de los asesores neutrales es un riesgo.

Cuarto, puede ser difícil frenar a un líder de la burocracia de asesores neutrales que intente ampliar su imperio burocrático. A fin de obtener el apoyo necesario para aumentar su presupuesto, estos líderes pueden ofrecer servicios de valor electoral a los parlamentarios. Así, el líder puede destinar a asesores supuestamente neutrales a desempeñar asesorías personales a ciertos parlamentarios clave, por la vía de delegar informalmente al parlamentario beneficiado las decisiones de selección, promoción y despido. Un segundo ejemplo es destinar asesores supuestamente neutrales a escribir discursos para el parlamentario beneficiado, donde el discurso sigue las pautas dictadas por éste. Un tercer ejemplo es un "Informe Distrital" que produce estadísticas con detalle a nivel distrital respecto al número de beneficiarios en el distrito de leyes aprobadas recientemente con el voto de los parlamentarios de ese distrito ${ }^{16}$.

De ocurrir esta transformación parcial de la asesoría neutral en asesoría personal, se abre una red de sospechas mutuas entre los parlamentarios respecto a quién está siendo favorecido con más intensidad por la burocracia supuestamente neutra. Además, se repite el virtual desvío de fondos públicos en favor de la campaña de reelección de los parlamentarios titulares, en perjuicio de los candidatos desafiantes y la ciudadanía.

En Chile todas las instancias que hemos señalado como parte de la asesoría neutral declaran, en forma más o menos explícita según el caso, ser neutrales y técnicas. Así por ejemplo, la Oficina de Informaciones de la Cámara de Diputados señala que en sus informes se expresa la opinión del profesional que lo escribe "elaborada en la forma más objetiva posible”17. Sin embargo, no hay claridad para dilucidar

${ }^{16}$ En Chile, la BCN presta estos servicios, llamados "Informe Distrital” y "Brochure Digital”, desde 2007. La BCN está considerando ofrecer a los parlamentarios "textos guiados", que son discursos (que se les regalan) adaptados u "orientados" por la ideología o estilo personal del parlamentario en particular.

${ }^{17}$ Oficina de Informaciones de la Cámara de Diputados: informe "Recursos y Fuentes de Información a Disposición de los Diputados”, p. 28. 
cómo se alcanza ese grado de neutralidad y objetividad en temas donde, por cuestiones de principios o ideología, no hay una solución netamente técnica. Ni la BCN ni las oficinas de informaciones de ambas cámaras tienen una política clara de aproximación a los temas en debate y en ocasiones los informes que elaboran toman partido por una determinada postura que, a juicio de muchos de los legisladores que participan en el debate, no es la que corresponde.

Esto ocurre en menor grado en instancias similares en el Congreso de Estados Unidos. La diferencia parece explicarse por la ausencia en Chile de una tradición fuerte, de códigos de conducta confiables, y de normas claras y conocidas que limiten la capacidad de comprometer opiniones. Por ello es más probable que en Chile las instancias que prestan asesoría neutral se transformen en instancias dependientes de un sector político. Ello podría evitarse si, con la reforma que se propone aquí, se establece una competencia sólida para la asesoría neutral, que la obligue a perfeccionarse.

\section{PROPUESTA DE REFORMA DEL SISTEMA DE ASESORÍA PARLAMENTARIA}

La mejor garantía de que los parlamentarios se independizarán de los lobbies y de las asesorías del Poder Ejecutivo es el pluralismo en la asesoría legislativa que reciban, unido a una capacidad interna suficiente para procesar la información recibida. No es razonable comprar asesoría externa cuando no se cuenta con la capacidad interna para evaluar y utilizar esa información. Si la asesoría externa es regalada, mejor, pero la gratuidad eleva la importancia de evaluar esa información con expertos de confianza.

El primer punto — pluralismo — lleva a fomentar la competencia entre diferentes fuentes de asesoría legislativa, y a evitar el monopolio que resultaría si se limitaran los recursos públicos a la asesoría legislativa "neutral". Por ello se propone ampliar el programa de compra de asesoría legislativa externa y revisar el modelo actual de asesoría neutral.

El segundo punto exige crear un nuevo sistema de asesoría legislativa interna que cuente con la confianza política de los parlamentarios asesorados. Esta asesoría es la que ayudará a los parlamentarios a procesar las demás asesorías que reciben. 


\subsection{Propuesta para crear una nueva asesoría legislativa interna}

La propuesta es adoptar un modelo donde cada asesor legislativo interno dependa de un Comité (partidista) ${ }^{18}$, en una rama del Congreso. Se propone una jefatura múltiple, en parte integrada por todos los parlamentarios que integran el Comité, y en parte por una Comisión de Evaluación más pequeña, elegida de entre los miembros del Comité.

Esta propuesta busca combinar filtros para, por una parte, contratar efectivamente a asesores legislativos y no activistas distritales, y por la otra, permitir que se contrate a personas que den confianza política y técnica a los parlamentarios. Esta confianza se fundaría en una comunidad de principios, asociados al partido representado en el Comité, que permitirá empoderar a los asesores.

Hoy, los legisladores en las comisiones deben discutir todos los artículos de un proyecto de ley y cada una de las modificaciones presentadas. Nuestra propuesta aspira a una tramitación legislativa más eficiente, donde el tiempo de los legisladores y de las discusiones en comisión se concentre en los puntos más relevantes, dejando la revisión de los temas menos importantes a los asesores. La definición de qué es importante y qué se delega se entrega a los propios parlamentarios.

El número total de asesores dependerá del presupuesto que se destine a este ítem. Proponemos que la distribución de los cupos de asesores entre los diversos comités sea proporcional a los escaños. Por tanto, dependerá de la representación que cada uno de ellos tenga, ya sea en la Cámara de Diputados o en el Senado. Los comités más grandes tendrán más asesores, pues tienen mayor presencia legislativa y más apoyo electoral.

La propuesta considera diversos componentes que se detallan a continuación ${ }^{19}$.

Proceso de selección. El proceso de selección se divide en tres etapas. En la primera, el secretario (neutral) de cada cámara convoca a concurso público para llenar los cargos disponibles en cada comité y

${ }^{18}$ Los comités son los organismos que agrupan a un número de diputados o senadores de un mismo partido y que son dirigidos por un jefe de comité que se relaciona con la mesa de cada corporación para hacer más expedita la tramitación de la ley.

${ }^{19}$ Algunos de los aspectos que se proponen a continuación fueron planteados antes por Blanco, Buchheister, Díaz-Tendero y Venegas (2006). 
opera como un primer filtro que verifica únicamente el cumplimiento de ciertos requisitos formales (título profesional y cumplimiento de ciertos estándares mínimos). Cada postulante debe señalar previamente el Comité donde pretende ejercer como asesor, pues, dada la necesaria comunidad de principios que debe existir entre los asesores y los parlamentarios, resultaría irrisorio que fuera indiferente la tendencia política del asesor que postula. Luego el secretario envía a cada Comité el listado de los postulantes que han superado ese primer proceso de selección.

Comisión de Evaluación. Cada Comité designa una Comisión de Evaluación. Para que en cada Comisión de Evaluación estén presentes las corrientes internas que suelen existir en los Comités, deberán integrarlo tres miembros. Esos tres miembros serán elegidos por el conjunto de todos los integrantes del Comité (bancada), de entre ellos mismos. La Comisión estará integrada por aquellos legisladores que hubieren obtenido el mayor número de votos en una única votación al interior de su Comité, en la que cada miembro votaría hasta por dos candidatos sin acumular. Esta regla garantiza que al menos puedan tener representación al interior de esta comisión hasta dos corrientes internas (la primera y segunda mayoría), a menos que la mayoría tenga más de dos tercios de todos los miembros del Comité. La tercera pluralidad y otras menores, si las hubiera, pueden también coordinar su votación.

La Comisión de Evaluación evalúa a los postulantes a los cargos de asesor legislativo y después de realizar una preselección de candidatos, los presenta al Comité (bancada). Cada una de las postulaciones debe ser aprobada por separado y por el Comité en pleno, en una sola votación que debe reunir al menos 2/3 de votos favorables de los integrantes del Comité. Los candidatos que no alcancen esa votación quedarán descartados.

El procedimiento recién descrito es enteramente aplicable a la Cámara de Diputados pero podría no serlo en el caso del Senado, pues allí existen Comités (bancadas) integrados por menos de tres senadores. Cuando eso ocurra, la Comisión de Selección sería integrada por todos los legisladores que formen parte del Comité.

Estructura y funcionamiento. Cada Comité designará a un Jefe de Asesores entre los asesores elegidos previamente por el Comité. El Jefe 
de Asesores coordinará el trabajo de los asesores y actuará como jefe directo de ellos, a su vez actuará como vínculo de los asesores con el Comité y con el Jefe de Bancada ${ }^{20}$. Además, quien ocupe este cargo podrá tener algunos derechos especiales, como la posibilidad de entrar a la sala de sesiones.

Los asesores se distribuirán por comisiones temáticas según lo determine cada Comité. Se establecerá además un catálogo de derechos, obligaciones y prohibiciones para los asesores legislativos, de forma tal de garantizar la asesoría y la independencia de los grupos de presión y los lobbies.

Transparencia y rendición de cuentas. Los asesores tendrán la obligación de asistir a comisiones y de elaborar ciertos informes periódicos y estandarizados en que se rinda cuenta pública del trabajo de cada uno. Se espera que la vigilancia de los rivales y de los medios de comunicación, unida a la vigilancia de los miembros de cada Comité que no integran la Comisión de Evaluación, y la vigilancia propuesta a continuación impidan una colusión entre los parlamentarios para repartirse los asesores para enviarlos al trabajo distrital.

Evaluación y remoción. Los asesores y el Jefe de Asesores no se incorporarán a una carrera funcionaria y son por ello de confianza exclusiva de cada uno de los Comités. Para estos efectos la misma Comisión de Evaluación que selecciona a los asesores asumirá la tarea de evaluar anualmente a cada uno de ellos, utilizando diversas herramientas. Entre otras, podrían considerar los informes periódicos estandarizados que deben realizar los asesores; encuestas a los parlamentarios miembros del Comité, encuestas a otros funcionarios del Congreso que participan en el proceso de formación de la ley; informes del Jefe de Asesores y otros medios de evaluación que se determinen. La evaluación no tendrá efectos automáticos, pero eventualmente dará lugar a la remoción del asesor si así lo estima la Comisión de Evaluación. En todo caso, siempre servirá como antecedente calificado para futuras postulaciones. Además, al menos algunos de los antecedentes que se incorporan a la evaluación deberán ser públicos, como los informes estandarizados y el resultado global de las encuestas de opinión.

20 Jefe de Bancada es el legislador que representa a un Comité parlamentario, o al conjunto de ellos, si existieren varios comités de un mismo partido. 
Adicionalmente, se propone que cada asesor pueda ser removido si concurren algunas causales establecidas en el reglamento que los rija, las que deberán incluir la pérdida de confianza política y el incumplimiento de las tareas encomendadas con la eficiencia requerida. La decisión de remoción podrá ser solicitada por el Jefe de Asesores, por el Jefe de bancada o por cualquier diputado. La Comisión de Evaluación resolverá por mayoría.

Los asesores cesarán en el ejercicio de sus funciones de pleno derecho una vez que cese el período legislativo para el cual fueron elegidos, esto es, al final de los cuatro años. Llegada esta fecha, se inicia nuevamente un proceso de selección donde asesores antiguos y nuevos interesados pueden concursar.

Remuneraciones. Para ganar la confianza ciudadana, es necesario que las remuneraciones de los asesores no sean determinadas por los parlamentarios, pues de lo contrario se sospechará que reparten estos puestos a sus amistades y leales. Se propone que una vez seleccionado un asesor, su remuneración sea determinada por el Consejo de la Alta Dirección Pública (u otro organismo análogo), que la establecería sobre la base de antecedentes objetivos basados en la historia laboral del postulante. El concepto es que el sueldo no sea más atractivo para el postulante que sus sueldos anteriores, pues el honor de servir a la nación debería bastar para hacer más atractivo el trabajo de asesor. Ese Consejo también establecería requisitos de dedicación y encargaría a un ente independiente la vigilancia de su cumplimiento, entre los cuales debería considerarse al Jefe de bancada del mismo partido en la otra cámara del Congreso. El asesor mantendría la opción de rechazar la nominación.

Número de asesores en el nuevo programa. Se propone que el número de asesores por Comité se distribuya proporcionalmente según el número de diputados y senadores. Se propone financiar un número preliminar total de 30 asesores para los 38 senadores y de 60 asesores para los 120 diputados, incluyendo jefes de asesores. Sin embargo, la necesidad de evitar fracciones de asesor obliga a tener un margen de flexibilidad. Se propone que se itere en la proporcionalidad hasta que se obtenga el primer conjunto entero de asesores cuya suma exceda la cantidad preliminar. Se propone financiar este número adicional de asesores. 
CUADRO N ${ }^{\circ}$ 1: $\quad$ PERSONAL PROPUESTO PARA EL NUEVO PROGRAMA DE ASESORÍA LEGISLATIVA: EJERCICIO ILUSTRATIVO

\begin{tabular}{|c|c|c|c|c|c|c|c|c|}
\hline $\begin{array}{l}\text { Senado } \\
\text { Comité }\end{array}$ & DC & PPD & PR & PS & INDEP & $\mathrm{RN}$ & UDI & Total \\
\hline $\mathrm{N}^{\circ}$ de senadores & 5 & 2 & 3 & 8 & 4 & 7 & 9 & 38 \\
\hline Asignación proporcional & 3,95 & 1,58 & 2,37 & 6,32 & 3,16 & 5,53 & 7,11 & 30,00 \\
\hline Entero más cercano & 4,0 & 2,0 & 2,0 & 6,0 & 3,0 & 6,0 & 7,0 & 30 \\
\hline $\begin{array}{l}\text { Cámara de Diputados } \\
\text { Comité }\end{array}$ & DC & PPD & PR & PS & INDEP & $\mathrm{RN}$ & UDI & Total \\
\hline $\mathrm{N}^{\mathrm{o}}$ de diputados & 16 & 19 & 7 & 16 & 7 & 22 & 33 & 120 \\
\hline Asignación proporcional & 8,00 & 9,50 & 3,50 & 8,00 & 3,50 & 11,00 & 16,50 & 60,00 \\
\hline Entero más cercano & 8,0 & 9,0 & 3,0 & 8,0 & 3,0 & 11,0 & 16,0 & 58 \\
\hline $\begin{array}{l}2^{\mathrm{a}} \text { iteración: aumento } \\
\text { proporcional }\end{array}$ & 8,28 & 9,83 & 3,62 & 8,28 & 3,62 & 11,38 & 17,07 & \\
\hline Entero más cercano & 8,0 & 10,0 & 4,0 & 8,0 & 4,0 & 11,0 & 17,0 & 62 \\
\hline
\end{tabular}

Esta propuesta se ilustra en el Cuadro $\mathrm{N}^{\circ} 1$. En el escenario actual, el cuadro muestra el número de escaños de cada Comité (bancada), el número de asesores que correspondería proporcionalmente a cada uno, la aproximación al entero más cercano y la suma resultante. En el caso del Senado, esta suma coincide con el número total preliminar y el proceso se detiene allí. En cambio, en la Cámara la suma es inferior al número total preliminar, por lo que se procede a una segunda iteración. En ella, la nueva suma de enteros produce un exceso de dos asesores. Se propone financiar este exceso respecto del número total preliminar y detener el proceso allí.

Los números propuestos en el Cuadro $\mathrm{N}^{\circ} 1$ permitirían que cada Comité tenga asesores en todas las comisiones temáticas ${ }^{21}$ pero, al mismo tiempo, no exige ni impone la presencia de asesores de todos los Comités en todas las comisiones temáticas. De acuerdo al criterio de cada Comité, sus asesores serán distribuidos en las comisiones temáticas, pudiendo concentrarse en algunas o destinar a algunos asesores a participar en más de una comisión temática. Así, habrá comi-

${ }^{21}$ En la Cámara de Diputados hay 22 comisiones permanentes, además de un sinnúmero de especiales e investigadoras. En el Senado hay 20 comisiones permanentes. 
siones temáticas sin asesores representantes de algunos comités, así como hoy existen comités que no tienen representantes en ciertas comisiones. Notemos también que la "bancada independiente" también recibe asesores.

Cambios de partido. Si un parlamentario abandona un partido, o si se forma un partido nuevo, cambiaría el número de miembros en cada Comité (bancada) y habría que reasignar a los asesores legislativos. Sin embargo, ello no puede permitirse en cualquier momento, ni en forma intempestiva, sin poner en peligro la especialización y la carrera de los asesores. Para conciliar ambos objetivos, se propone limitar los rebalanceos exclusivamente a la fecha en que se cumple la mitad del período parlamentario, y limitar los cambios a rebalanceos positivos. En otras palabras, se podría contratar un nuevo asesor a raíz de un rebalanceo, pero ningún asesor sería despedido por este motivo.

Ventajas de la propuesta. Como se ha señalado, la propuesta hace depender el nuevo sistema de asesoría legislativa de los comités. Este sistema presenta diversas ventajas además de otras desventajas que se plantean a continuación.

Comparando con la asesoría personal, este esquema reduce el riesgo de que un parlamentario integrante de la Comisión de Evaluación desvíe el trabajo de un asesor hacia labores en su distrito, pues enfrentaría la competencia de los otros dos miembros de la Comisión de Evaluación y, en general, de todos los otros miembros del Comité que también quisieran desviar asesores hacia su propio distrito. Un acuerdo para dividirse los asesores entre los tres integrantes de la Comisión de Evaluación y replicar la asesoría personal también es improbable, porque provocaría el rechazo de los otros parlamentarios que integran el Comité pero no la Comisión de Evaluación. Tampoco es factible repartirse los asesores entre todos los miembros del Comité, porque el número de asesores es inferior al de parlamentarios miembros. En esta situación, parece probable que los asesores sean destinados a una labor legislativa real.

Es posible que existan conflictos entre parlamentarios porque un asesor de una Comisión temática promueva un punto de vista exigido por un subconjunto de miembros del Comité (bancada), en contra del punto de vista exigido por otros miembros. Creemos que el Comité de Evaluación y el Jefe de Asesores podrán dirimir estos conflictos. 
Si se compara con la "asesoría neutral", este esquema tiene la ventaja de una mayor cercanía entre asesores y parlamentarios, pues construye lealtades alrededor de la afinidad partidista. Como ya se ha dicho, la asesoría legislativa para ser efectiva siempre debe involucrar cierta comunidad de principios y una visión común de cómo abordar las temáticas que se discuten. Esto permite que el asesor esté empoderado y pueda realizar un trabajo efectivo. La asesoría neutral, como se ha visto, es incompatible, por definición, con una comunidad de principios de todos los legisladores del Congreso Nacional. Por eso, sólo puede aspirar a prestar apoyo entregando información sobre las diversas posturas en juego. El sistema que se propone permite que la información entregada, entre otros por la asesoría neutral, sea contrastada con los principios e idearios de cada Comité y así presentada al legislador. Esto aumenta la probabilidad de que los legisladores otorguen consideración real al trabajo de los asesores y se establezcan vínculos de confianza que los hagan más efectivos en el tiempo.

Adicionalmente, la propuesta evita la creación de una burocracia que no rinda cuentas a nadie, disminuyendo así el peligro de que se generen imperios burocráticos forjados a través del intercambio de favores con los parlamentarios.

Otra ventaja de la asesoría estructurada sobre la base de los comités es que en la práctica estos asesores serían parte del equipo del partido político respectivo, potenciando así el rol legislativo de cada una de las colectividades. La asesoría legislativa personal elevaría los recursos disponibles para el parlamentario que intente diferenciarse ante la opinión pública por medio de una estrategia de “díscolo”, mientras que la asesoría por Comité retira dichos recursos y prioriza un crédito colectivo al partido, que contribuiría a prestigiarlo ante la opinión pública.

Como el Comité es mucho más duradero que los cargos parlamentarios individuales, la permanencia de los asesores de Comité podría ser sustancial, creando espacio para una carrera profesional extensa. No es ésta una carrera funcionaria al estilo de las que conocemos en la administración pública, donde hay escasos incentivos a hacer las cosas bien. Como se ha planteado, todos los asesores cesan de pleno derecho al renovarse cada una de las cámaras, lo que los obliga nuevamente a concursar. Aun en este escenario es probable que se forme una carrera profesional para los asesores. Ello a su vez permite la especialización y profesionalización. Esto no es mera teoría, porque 
ha sido documentado empíricamente en el Congreso de EE.UU. respecto de los asesores que cada uno de los partidos designa en las comisiones temáticas que han adoptado ese sistema (Salisbury y Shepsle, 1981, p. 389, citado por Simon y Cohen, 1983).

Otro resultado de esta propuesta sería un fortalecimiento de hecho de cada partido, al dotarlo de presupuesto para remunerar personal calificado en el Congreso. Al estar estos asesores enfocados a problemas de políticas públicas en profundidad, los partidos podrán desarrollar con más detalle sus propuestas a la ciudadanía.

Prevenciones y medidas propuestas. La contracara de las ventajas ya descritas es el peligro de mal uso de la influencia. En efecto, los asesores que logren experiencia y conocimientos sustanciales adquirirán influencia sobre el voto de sus parlamentarios, sobre el contenido del texto legislativo y sobre la agenda sectorial.

Una consecuencia de esta influencia es convertirlos en un blanco apetecido para los grupos de interés y los lobbies. Los asesores valorarán —y con razón - el acceso a información que pueden ofrecer los lobbies, así que esta relación tiene aspectos positivos. Sin embargo, también podrían valorar otras ofertas de los lobbies que son beneficios privados para el asesor legislativo, incluyendo empleos futuros o regalos. Incluso cabría imaginar casos donde un asesor legislativo amenace con dañar a un lobby a menos que éste le preste un beneficio de carácter privado.

Para evitarlo, el modelo de asesoría que se propone debe ser complementado con transparencia y medidas específicas de control de conflictos de interés para asesores legislativos, que incluya un régimen de incompatibilidades antes, durante, y después de ejercer la función. En especial, debe crearse un régimen de incompatibilidades para los asesores que no tengan dedicación completa, y que por tanto quedan en condiciones de realizar asesorías a lobbies en la parte de su jornada no comprometida con el Congreso. Se recomienda exigir que los asesores sin dedicación exclusiva sólo puedan desempeñarse en institutos de partidos políticos y en docencia durante sus horas no comprometidas, con una excepción. Esta excepción se aplicaría a personas de amplia experiencia y reputación intachable, previamente calificadas por la misma Comisión que fija las remuneraciones. El número de excepciones sería bajo. 
Un segundo problema con el asesor legislativo exitoso es que podría usar su influencia para desarrollar una agenda propia fuera del control de su Comité, sea de carácter ideológico (i. e., la agenda medioambiental, la agenda anti-Estado), o en favor de un segmento demográfico (i. e., la agenda de los pueblos originarios, la feminista). Algunos advierten que esta influencia podría debilitar el proceso deliberativo general (Malbin 1980, pp. 247-248, citado por Simon y Cohen, 2003).

Para evitar la aparición de este segundo problema, la institucionalidad que se propone permite el control de los asesores por parte del Comité (el partido). En la estructura que se ha propuesto hay mecanismos de remoción permanentes que pueden ser activados por cualquier legislador. Es probable que si un asesor empieza a desarrollar una agenda propia a espaldas de los parlamentarios que integran su Comité, y es detectado, se activen estos mecanismos. También disminuyen las probabilidades de que ello ocurra si se crean suficientes cupos de asesores en cada Comité, para que ningún asesor individual pueda construir un monopolio de la experticia en un tema dado. Desde luego, eso no es suficiente cuando el Comité entero está dispuesto a ceder el control sobre ciertos asesores para congraciarse con determinado grupo de presión o lobby. Sin embargo, esta forma de corrupción es menos probable en el caso de un Comité, comparado con el caso donde un parlamentario designa asesores personales en forma autónoma, porque existe vigilancia de los demás miembros del Comité y de la directiva del partido político.

Otra posible desventaja de los comités partidistas es que la multiplicidad de jefaturas podría debilitar la rendición de cuentas. En efecto, si cada miembro del Comité intenta traspasar las tareas de control a los demás colegas, y en definitiva nadie las asume, los asesores quedarían libres de exigencias y de rendir cuentas. A este respecto se sugieren dos soluciones que son complementarias:

a) Asignar la responsabilidad por la rendición de cuentas y evaluación de los asesores a la Comisión de Evaluación, sea por ley o por reglamento de cada cámara, y

b) Autorizar explícitamente a cada uno de los comités a delegar parte de esta tarea a funcionarios del partido político al cual está afiliado, previo acuerdo formal de la mesa directiva del partido respectivo. Esta segunda solución también contribuye a fortalecer el vínculo con los partidos. 
En otra dirección, los parlamentarios que integran la Comisión de Evaluación pueden usar su influencia sobre los asesores legislativos para destacar y mejorar su imagen, y esto podría ocurrir a costa de la oscuridad de los demás legisladores que integran el Comité, pero que no integran dicha Comisión. Más en general, es previsible que dichos miembros sientan que su acceso a asesorías de calidad está limitado por las prioridades decididas por la Comisión de Evaluación, que pueden diferir de las suyas. Esta discrepancia aumenta cuando dicho parlamentario siente ser un rival potencial, al interior del partido, de quienes controlan la Comisión de Evaluación ${ }^{22}$.

Con la fórmula descrita para elegir a la Comisión de Evaluación se espera evitar la ocurrencia de esa potencial situación. Esta fórmula permite que a ella lleguen no sólo la corriente mayoritaria dentro el Comité sino también la segunda pluralidad dentro del mismo Comité. También convendría crear un mecanismo simple para poder nominar a una nueva Comisión en caso de solicitarlo un número determinado de legisladores que integran el Comité. De este modo, se permitirá adecuar la integración de cada Comisión de Evaluación a los cambios en las mayorías al interior de cada Comité. Si bien es probable que la nueva Comisión nombrada no ponga término al contrato de los asesores en ejercicio, al menos podrá dar nuevas pautas o imponer otros mecanismos de rendición de cuentas.

\subsection{Propuesta de expansión de la asesoría legislativa externa}

Para que los parlamentarios se independicen en mayor medida de los lobbies y de las asesorías del Poder Ejecutivo, se propone ampliar y perfeccionar el programa de compra de asesoría legislativa externa, de manera de fomentar la competencia.

Es natural excluir a los lobbies del conjunto de entidades externas que pueden postular a este financiamiento. La asesoría de un grupo de presión o lobby no merece financiamiento especial del Congreso, aunque se trate del lobby de grupos con pocos recursos económicos, porque dichos grupos promueven intereses privados o de grupo, no el interés general.

22 Esta rivalidad ayuda a explicar por qué el sistema de financiamiento para institutos de partido, creado en el Congreso chileno a fines de los años 90, no se expandió y es considerado poco exitoso. 
En general, el financiamiento público debería estar reservado sólo a entidades que provean un filtro suficiente de los intereses particulares en favor del interés general. Las asesorías legislativas de institutos asociados a partidos y las de think tanks podrían no tener suficiente independencia si ellos reciben aportes significativos de lobbies y del Poder Ejecutivo.

Se propone diseñar una acreditación que certifique un nivel suficiente de independencia de intereses particulares, y condicionar el acceso a los recursos públicos para la obtención de esa acreditación. En particular, se recomienda crear estándares para la independencia del personal que hace la asesoría legislativa en dichos institutos y think tanks, respecto de lobbies y del Poder Ejecutivo. El diseño de estos estándares es una tarea que debiera ser encargada en una licitación internacional por la Secretaría de las cámaras, actuando en conjunto, a personas independientes de quienes estarán sujetos a dichos estándares en el futuro.

Es natural suponer que el Poder Ejecutivo tendrá interés en minimizar los fondos de asesoría externa, pues ellos fortalecen a rivales potenciales, empezando por los legisladores de oposición. Esa aspiración puede ser materializada fácilmente en Chile, porque la Constitución entrega al Poder Ejecutivo casi todas las facultades para determinar el presupuesto anual. Por este motivo, se propone fijar por ley el presupuesto de asesorías externas, en una suma externa que guarde relación con la complejidad del Estado y de la legislación. En concreto, proponemos que este presupuesto sea una fracción fija, por ejemplo 5\%, del gasto en remuneraciones al personal incorporado al Sistema de la Alta Dirección Pública, en el mismo año fiscal.

También se propone compensar el acceso asimétrico, y por tanto privilegiado, a la asesoría del Poder Ejecutivo que tienen los parlamentarios oficialistas en desmedro de los parlamentarios de oposición. Para lograr este fin, se propone separar el presupuesto de asesorías externas en dos: un fondo controlado por parlamentarios de oposición e independientes y otro menor controlado por los parlamentarios oficialistas. El tamaño relativo del fondo oficialista debería fijarse en la ley en una suma igual a una tercera parte del fondo para asesorías a parlamentarios de oposición e independientes. Como estos recursos serían destinados exclusivamente a financiar asesorías otorgadas por institutos y think tanks previamente acreditados, no sería posible para 
un parlamentario díscolo acceder a estos recursos por la vía de renunciar a su partido y declararse independiente. Con el fin de evitar consideraciones de corto plazo, se propone que la división de los recursos en los dos fondos propuestos entre en vigor en el año fiscal 2013.

\subsection{Reestructuración de la asesoría neutral}

Ya se han planteado algunas deficiencias del sistema de asesoría neutral vigente hoy en nuestro país. Con todo, como se dijo, esta forma de asesoría está llamada a cumplir un rol importante de apoyo al trabajo legislativo, que amplía los antecedentes disponibles al momento de legislar, especialmente si desarrolla vínculos con oficinas análogas de otros países y facilita la adaptación de legislaciones extranjeras exitosas a la situación nacional. Si así operara el sistema de asesoría neutral, especialmente el que presta hoy la BCN, el trabajo de esta entidad se complementaría con el de los futuros asesores legislativos contratados según la fórmula que se ha propuesto. Estos últimos serían los receptores naturales de la información neutra y agregarían el prisma que le asigne cada ideario o Comité (partido).

Por esta razón, se recomienda que toda la asesoría neutral que existe hoy en el Congreso quede sujeta a nuevos códigos de conducta que limiten su capacidad de comprometer opiniones. Adicionalmente, y en lo que respecta a la BCN, se recomienda modificar el órgano directivo de esta institución. En la actualidad las directrices las da una comisión compuesta por tres personas: los Presidentes del Senado y de la Cámara de Diputados y la Directora de la BCN. Una institucionalidad que integre a otros dos miembros nominados por el Congreso, ojalá no legisladores, puede promover una rendición de cuentas más constante y, al mismo tiempo, evitar que el periódico cambio en las presidencias de las cámaras impida generar visiones de largo plazo.

Por otra parte, y como se vio, la asesoría legislativa neutral más importante, que es aquella referida a las oficinas de presupuesto, está hoy disminuida en ambas cámaras. Ello ha permitido que continúe una fiscalización escasa de la ejecución del gasto público por parte del Congreso Nacional. Recordando que en Chile la elaboración del presupuesto es una responsabilidad casi exclusiva del Poder Ejecutivo, no resulta recomendable que el Congreso aplique una fiscalización débil como la actual. Por esta razón conviene fortalecer las capacidades 
técnicas del Congreso en esta materia ${ }^{23}$. Para lograrlo, proponemos que una parte del personal que actualmente ejerce funciones de asesoría legislativa neutral en la BCN sea redestinado a prestar funciones a la Comisión Especial Mixta de Presupuestos (CEMP). Alternativamente, se propone que manteniendo la calidad de asesores neutrales de la BCN, una parte importante de ese personal sea destinada a la fiscalización del presupuesto ejecutado.

\section{ESTIMACIÓN DE COSTO FISCAL DE LA PROPUESTA}

En el programa de asesoría legislativa interna que hemos propuesto se contempla contratar 30 asesores para el Senado y 60 para la Cámara de Diputados El costo fiscal asociado incluye remuneraciones, arriendo de espacio físico, gastos de oficina, viáticos y remuneración de personal de apoyo. En atención a la calificación esperada y a un grado de dedicación variable, estimamos un costo fiscal bruto por todos estos conceptos de \$ 4 millones al mes por asesor, en promedio. Por ello, el costo fiscal de este nuevo programa se estima en $((30+60) x$ $\$ 4$ mill. x 12 meses =) \$ 4.320 millones al año.

En la expansión del programa de asesoría externa se propone que el nuevo presupuesto global sea un $5 \%$ del gasto en remuneraciones al personal incorporado al Sistema de la Alta Dirección Pública, en el mismo año fiscal. Debido a que en 2008 el SADP tenía 846 personas incorporadas, se trata de una suma equivalente a las remuneraciones brutas de unas 42 personas, cuyo promedio se estima en \$ 2,3 millones al mes. Sin embargo, todavía debe restarse el actual presupuesto del programa de asesoría externa de la Cámara, que fue \$ 329 millones en 2008. El resultado es que el costo fiscal de la expansión propuesta alcanza a \$ 840 millones al año. Si bien esta suma crecerá cuando aumente el número de altos directivos adscritos al SADP, en esa oportunidad se podrá revisar el porcentaje de $5 \%$ propuesto para la etapa inicial.

En suma, el costo presupuestario inicial de esta propuesta suma \$5.160 millones al año, es decir unos 8,9 millones de dólares al año. Creemos que éste es uno de los proyectos de inversión de mayor rentabilidad social que el sector público chileno tiene disponible en la actualidad.

${ }^{23}$ Cabe señalar que en los cincuenta estados de EE.UU. se utilizan staffers para el análisis del presupuesto de cada uno de esos estados. El trabajo de los asesores es de vital importancia (Hoffman, 2006). 


\section{Anexo \\ La experiencia del Congreso de los EE.UU. \\ con la asesoría legislativa}

En los EE.UU. el personal de apoyo en el Congreso federal supera en número a los parlamentarios en 45 veces (Ornstein, Mann, y Malbin, 1998, citado de Simon y Cohen, 2003). Hay cuatro tipos de personal (staffer), y sólo una parte de ellos son asesores legislativos propiamente tales (Romzek y Utter, 1996).

- $\quad$ Oficina personal del parlamentario: su labor combina la asesoría legislativa en los temas que interesan al parlamentario y el trabajo de mantener contacto directo con los residentes de su distrito a fin de lograr la reelección del parlamentario.

- Comisiones temáticas (Defensa, Agricultura, Protección Social, etc.): las comisiones son los lugares donde se estudia a fondo cada una de las propuestas de ley. En ellas se mezclan staffers de diversas procedencias. Algunos son expertos en la materia que trabajan para la comisión en forma permanente. Otros son asesores personales del presidente de la comisión, del líder de la minoría o de los demás integrantes (staff asociado a la comisión). En general, todos son profesionales con amplio conocimiento en la materia que corresponde a cada comisión. Cada una de éstas tiene un número variable de staffers trabajando para ella según las reglas internas y la importancia de la materia a la que se dedican. La labor primaria varía según la tradición de cada comisión temática. No hay carrera funcionaria para ninguno de estos funcionarios (Deering y Smith, 1997).

- Oficinas administrativas y comisiones conjuntas: este personal presta servicios en forma neutral y no partidista a todos los parlamentarios. Incluye el Congressional Research Service, el Congressional Budget Office y la Comisión Conjunta de Presupuestos.

- Oficinas de jefe de partido en el Congreso (sólo hay cuatro: dos del Partido Demócrata y dos del Partido Republicano, uno por cámara): la tarea principal es la coordinación de los votos de la respectiva coalición, administración del proceso legislativo (urgencias, otros) y negociaciones con el Poder Ejecutivo y la otra cámara. 
El número de empleados en las oficinas personales de la Cámara de Representantes varía entre 12 y 18, con una media de 15. En el Senado, el número de empleados en las oficinas personales varía entre 30 y 50, con un promedio de 34. En las comisiones temáticas, el personal varía entre 20 y sobre cien, en ambas cámaras (Congressional Management Foundation 1995, p. 19, citado por Romzek y Utter, 1996).

Este personal no está cubierto por las normas del servicio civil. En particular, no hay inamovilidad y sus puestos no están jerarquizados (Romzek y Utter, 1996). La ley indica que las decisiones de selección de personal y de remoción "deben estar basadas en la compatibilidad política” con el parlamentario a cargo (Dale et al., 1995). La ley (Congressional Accountability Act of 1995) exime al personal que es profesional de las normas sobre tiempo extra y horarios.

Estos puestos presentan los siguientes atributos especiales:

a) La carrera es corta. Un individuo talentoso puede pasar a ser un "veterano" en apenas cinco años. Esto facilita el reclutamiento, porque se puede tener impacto en áreas específicas en menos tiempo. Por otro lado, al ser corta la carrera las oportunidades de promoción terminan pronto, lo cual motiva las renuncias.

b) Una tasa de rotación extraordinariamente alta. La antigüedad media de los analistas legislativos es de tres años en la Cámara y cinco años en el Senado. En 1994, el 69 por ciento del personal de las oficinas personales de la Cámara que residía en Washington D.C. tenía 2 años o menos de antigüedad en su oficina. En cambio, asesores senior, como los asistentes administrativos, tenían una antigüedad media de 4 y 5 años para el Senado y la Cámara, respectivamente (Schultz, 1993 y 1994, citados por Romzek y Utter, 1996).

c) Los ocupantes son jóvenes. La edad promedio de los asesores legislativos es de 32 años (Schultz, 1993 y 1994, citados por Romzek y Utter, 1996).

d) Las horas trabajadas son más largas e impredecibles que en otros empleos. Se trabaja en espacios hacinados y sin privacidad. El empleado no tiene control sobre sus actividades de trabajo, pues está a disposición del parlamentario. No hay capacitación formal. Estas carencias se suplen reclutando personas ya educadas. El 64 por ciento llega con pregrado universitario completo y otro $22 \%$ llega con grados de máster o doctor. La remuneración es inferior a la de empleados de similar 
calificación del sector privado y del Poder Ejecutivo (Congressional Management Foundation, 1995, 1, citado por Romzek y Utter, 1996)

La ocasión más frecuente de egreso de esta carrera consiste en ser contratado para otro cargo, al que se ha accedido utilizando como credencial la experiencia en el Congreso (Salisbury y Shepsle, 1981). La mayoría de las salidas son planeadas, no sorpresivas. En el caso de egreso planeado, éste permite acceder a remuneraciones y condiciones de trabajo muy superiores. Ello explica las condiciones del punto d). La segunda ocasión más frecuente de egreso es la no reelección del parlamentario, ya sea porque perdió la elección o porque decidió no repostular. En este caso el egreso se acelera respecto del plan original.

Aquellos interesados en las políticas públicas con frecuencia se emplean en empresas dedicadas a hacer lobby, y en servicios públicos dependientes del Poder Ejecutivo federal o estadual. En ambos casos, el nuevo empleador valora la red de contactos formada en el Congreso federal. Aquellos interesados en los partidos mismos se dedican a asesorar campañas, para más adelante ser candidatos ellos mismos.

El ingreso a los puestos de la oficina personal está abierto en todos los niveles. Es común que ingresen personas provenientes de lobbies, grupos de interés, servicios públicos (Estado federal) y personal de campaña. Los puestos son llenados antes de que la vacancia sea ampliamente conocida. Ello se justifica como un medio para "evitar que algún lobbyst influyente o un donante de campaña nos imponga la contratación de un familiar". Para llenar los puestos más bajos, es frecuente contratar desde otras oficinas del Congreso. Se da prioridad a candidatos empleados previamente por parlamentarios del mismo partido, o de la misma facción dentro de un partido, o de la misma delegación estadual.

La situación es diferente para aquellos individuos que entraron o mantuvieron su carrera como asesores legislativos a edades mayores. Estos individuos suelen tener familia directa, no consideran necesario trabajar muchas horas, están radicados en la ciudad en forma permanente y están más interesados en hacer contribuciones significativas. También suelen manejar las unidades administrativas y tienen carreras largas.

Existe un debate en EE.UU. respecto a la tasa de rotación de la mayoría del personal del Congreso. Podría ser excesiva, y se notaría en la pérdida de experiencia que sufre el Congreso con cada egreso. Otros enfatizan que la experiencia no se pierde, sino que se transfiere a los 
nuevos empleadores. No se puede criticar que el Congreso subsidie entrenamiento para los futuros lobbysts, puesto que paga sueldos bajos y exige un trabajo duro. Por el contrario, los lobbysts subsidian al Congreso ofreciendo salarios altos que justifican la entrada a esta carrera. Salisbury y Shepsle (1981) sostienen que la alta rotación alimenta a la elite política más amplia, que incluye a los servicios públicos, lobbies, grupos de interés, medios de comunicación y universidades ${ }^{1}$.

\section{BIBLIOGRAFÍA}

Ampuero, H. (2006): “‘¡Fuera los Seconds!’ (o el papel de los ‘staffers’ y las asesorías políticas en el Congreso Nacional)”. Informe No 536, www.asuntospúblicos.org, 5 de mayo.

BID (Banco Interamericano de Desarrollo) (2005): The Politics of Policy: Economic and Social Progress in Latin America, 2006 Report. Ernesto Stein, Mariano Tommasi, Koldo Etchebarría, Eduardo Lora y Mark Payne (coordinadores). Washington D.C.: BID.

Blanco, Rafael, Axel Buchheister, Eolo Díaz-Tendero y Marcelo Venegas (2006): "Informe Final: Asesores Legislativos del Congreso Nacional. Proyecto Creación del Modelo del Programa Staffers”. Programa BID - BCN Innova.

Caplan, Bryan (2007): The Myth of the Rational Voter: Why Democracies Choose Bad Policies. Princeton University Press.

Consorcio de Centros de Estudio (2008): "Estudio Nacional sobre Partidos Políticos y Sistema Electoral”, marzo-abril. Este consorcio está integrado por Centro de Estudios Públicos, Cieplan, Libertad y Desarrollo: Proyectamérica y PNUD.

Dale, C., Robin Jeweler, Nancy Lee Jones, Jay R. Shampansky, Kathleen S. Swendiman y Vincent Treacy (1995): Congressional Accountability Act of 1995. Congressional Research Report. Washington D.C.: Library of Congress.

Datavoz (2006): Encuesta nacional de opinión pública. Imagen Congreso nacional.

Davidson, Roger y Walter Oleszek (2004): Congress and its Members. CQ Press, novena edición.

Deering, Christopher y Steven Smith (1997): Committees in Congress. CQ Press, tercera edición.

Godoy Arcaya, Óscar (2003): "Parlamento, Presidencialismo y Democracia Protegida”. En Revista de Ciencia Política, Volumen XXIII N 2, Santiago.

Hoffman, Kim (2006): "Legislative Fiscal Analysts: Influence in State Budget Development”. En State and Local Government Review Vol. 38 No 1.

Latinobarómetro (2008): Informe 2008. Corporación Latinobarómetro.

Meller, N. (1967): "Legislative Staff Services: Toxin, Specific, or Placebo for the Legislature's Ills”. En The Western Political Quarterly Vol. 20, № 2, Parte 1 (junio, 1967), pp. 381-389.

${ }^{1}$ Otra ventaja de la alta rotación es que reduce la influencia de los asesores legislativos. Un entrevistado propuso poner límites máximos a la permanencia de los asesores (no de los parlamentarios). 
Oelckers, O. (1993): “La Asesoría Legislativa en Chile”. En Centro de Estudios y Asistencia Legislativa, Universidad Católica de Valparaíso (comp.), Diagnóstico Histórico Jurídico del Poder Legislativo en Chile. Edic. Universitarias de Valparaíso.

Robinson, W. (2002): Knowledge and Power. The Essential Connection Between Research and the Work of Legislature. The European Centre for Parliamentary Research and Documentation.

Romzek, B. (2000): “Accountability of Congressional Staff”. En Journal of Public Administration Research and Theory Vol. 10, No 2: 413-446.

Romzek, B. y J. Utter (1996): “Career Dynamics of Congressional Legislative Staff: Preliminary Profile and Research Questions”. En Journal of Public Administration Research and Theory, Symposium Vol. 6, No 3: 415-442. - (1997): "Legislative Congressional Staff: Political Professionals or Clerks?”. En American Journal of Political Science Vol. 41, No 4 (octubre): 1251-1279.

Salisbury, R. y K. Shepsle (1981): “Congressional Staff Turnover and the Ties-ThatBird”. En American Political Science Review 75, pp. 381-396.

Siavelis M., Peter (2001): “Chile: Las Relaciones entre el Poder Ejecutivo y el Poder Legislativo después de Pinochet”. En Jorge Luis Lanzaro y Marcos Novaro (editores), Tipos de Presidencialismo y Coaliciones Políticas en América Latina. Clacso.

Simon, C. y L. Cohen (2003): "From Passive to Active Representation: The Case of Women Congressional Staff”. En Journal of Public Administration Research and Theory, Vol. 13, № 1: 65-82.

Valdés, S. (2008): "Financiamiento Político para Profundizar la Democracia”. En serie Puntos de Referencia No 294, agosto, Centro de Estudios Públicos, Santiago 